isolated or fastidious bacteria; approved guideline-second edition. Wayne, PA: CLSI; 2010. CLSI document M45-A2.

9. Horan TC, Andrus M, Dudeck MA. CDC/NHSN surveillance definition of health care-associated infection in the acute care setting. Am J Infect Control 2008;36:309-332.

10. Mermel LA, Allon M, Bouza E, et al. Clinical practice guidelines for the diagnosis and management of intravascular catheterrelated infection: 2009 updated by the Infectious Diseases Society of America. Clin Infect Dis 2009;49:1-45.

\section{Tuberculosis Infection Control: Potential Benefit of a New Rapid Tuberculosis Test in a Human Immunodeficiency Virus/AIDS Reference Hospital}

To the Editor-The risk of nosocomial transmission of tuberculosis (TB) to healthcare workers (HCWs) is well known $^{1}$ and is a major challenge in developing countries. ${ }^{2}$ The risk to HCWs is related to the number of patients with known smear-positive TB admitted to the hospital ${ }^{3}$ and whether effective infection control measures are in place. ${ }^{4}$ Brazil has clear guidelines for TB infection control, which include the rapid assessment of patients with suspected cases of $\mathrm{TB}$ to establish their infectiousness, the use of airborne precautions, and prompt treatment of smear-positive or highly suspected cases. ${ }^{5}$ In high-income countries, the prevalence of latent TB infection (LTBI) decreased from $0.1 \%$ $10.0 \%$ before 1995 to $0.1 \%-1.2 \%$ after infection control measures were implemented. ${ }^{6}$ In low- and middle-income countries, a systematic review showed a prevalence of LTBI of $54 \%$ and an attributable TB risk among HCWs, compared with the general population, ranging from 25 to 5,361 cases per 100,000 population. $^{2}$ The World Health Organization (WHO) recommends the implementation of new technologies for earlier diagnosis of TB, aiming to reduce transmission, including in healthcare settings. ${ }^{7}$ Although the Xpert MTB/RIF (GeneXpert) test is approved for the diagnosis of $\mathrm{TB}^{7}$ no study has, to our knowledge, evaluated its potential benefit in reducing nosocomial transmission.

We aimed to evaluate the time to sputum test results in routine conditions at an infectious disease reference hospital in Manaus, Brazil, a city with a TB incidence rate of 67.3 cases per 100,000 inhabitants in $2011 .{ }^{8}$ Patients whose sputum samples were sent to smear microscopy (SSM) examination from January 1 to May 16, 2012, or Xpert from May 31 to October 29, 2012, during a stepped-wedge rollout study to implement Xpert in Brazil $^{8}$ were included. Patients' demographic characteristics (sex and age), hospital location when TB was first suspected, HIV status, time in hours from laboratory request to laboratory result availability, and test results were extracted from electronic records. Statistical analysis was performed using Stata 11.2 (StataCorp). Pearson $\chi^{2}$ test was used to compare proportions, and a Kaplan-Meier curve with log-rank and Peto tests was performed to compare time differences. Statistical significance was established at 5\%. When dates, but not hours, were available at the electronic laboratory register, the mean number of hours per period and number of days difference were then imputed. The parent rollout study was approved by the national ethical board (CONEP 630/2010) and by the institutional review board (Fundação de Medicina Tropical Heitor Vieira Dourado, dated November 24, 2011).

We collected information from 270 patients, including 142 with SSM and 128 with Xpert test results. Eighteen patients in the SSM group $(12.7 \%$ [95\% confidence interval (CI), $7.7 \%-19.3 \%])$ and 19 patients in the Xpert group $(14.8 \%$ [95\% CI, 9.2\%-22.2\%]) had positive results. Among the latter patients, $2(10.5 \%)$ had results positive for rifampin resistance.

More participants in the Xpert group than in the SSM group were male $(67.2 \%$ vs $54.9 \% ; P=.039)$ and had suspected TB at admission to the emergency department $(56.3 \%$ vs $43.4 \% ; P=.094$ ). The median age was similar (37 vs 35 years; $P=.663$ ).

Although there was no difference in median time in hours (6.8 hours [interquartile range (IQR), 6.2-10.0 hours]) versus the SSM group (15.0 hours [IQR, 4.2-26.5]; $P=.117$ ), the Kaplan-Meier curve with time from request to test results by period showed a shorter time using Xpert. Both the log-rank and the Peto tests were significant $(P<.001$; Figure 1$)$.

Although one would expect the laboratory turnaround time to be similar between the SSM and Xpert groups, the difference in reporting time is probably attributable to the result of operational issues in the laboratory and laboratory reporting system. This fact would indicate that our results are specific to our setting and not amenable to be applied to

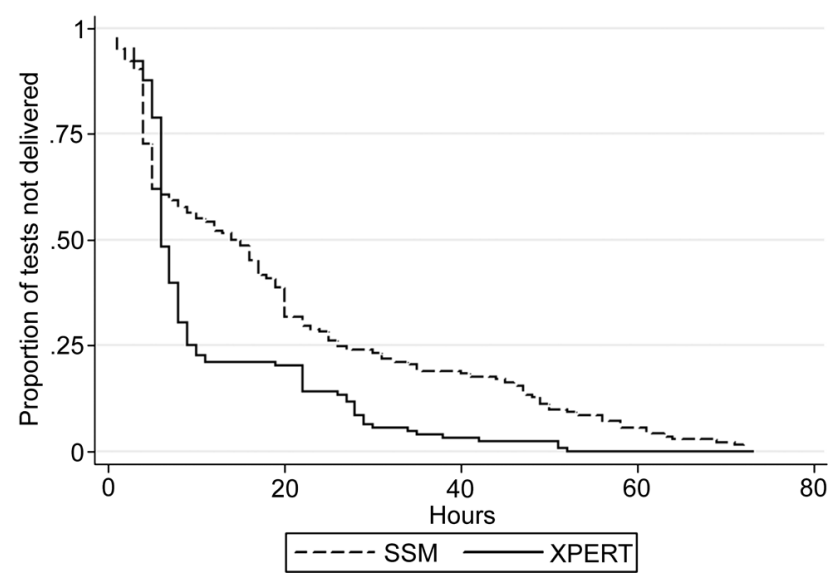

FIGURE 1. Kaplan-Meier curve with time for test results by period, Fundação de Medicina Tropical Heitor Vieira Dourado (FMT-HVD; Manaus, Brazil), 2012. Data are from the laboratory electronic data registry, FMT-HVD, 2012. SSM, sputum smear microscopy; XPERT, Xpert MTB/RIF test (GeneXpert). 
other settings. However, the introduction of new technology requires revision of work processes that would likely be the same in different hospitals.

The use of Xpert may contribute to improved TB infection control through identification of SSM-negative patients and detection of rifampin resistance, which would bring greater concern to HCWs and other patients and prompt earlier identification of potentially multidrug-resistant TB.

We conclude that this new technology allows for faster diagnosis of $\mathrm{TB}$, which would prompt earlier institution of TB therapy and therefore potentially reduce the odds of $\mathrm{TB}$ transmission to HCWs. Implementation of TB infection control measures in healthcare facilities has been on the agenda for a long while, and delays in TB therapy initiation are a major contributor to HCWs' increased risk. ${ }^{9}$ Furthermore, a positive result for rifampin resistance is a good marker of multidrug-resistant $\mathrm{TB}$ and should prompt a thorough search for secondary cases and LTBI, including among HCWs. However, technology alone does not change health policies and practices, including those of HCWs, at the same pace. ${ }^{10}$ In summary, our findings suggest a potential benefit of Xpert for TB infection control in the hospital setting. However, implementation of infection control measures remains a priority for HCW protection.

\section{ACKNOWLEDGMENTS}

Financial support. This work was supported by the InCo-TB project, a partnership of Brazilian National TB Program and the Fundação Ataulpho de Paiva Foundation, funded by the Bill and Melinda Gates Foundation (OPPGH 5254) and Fundação de Amparo à Pesquisa do Estado do Amazonas.

Potential conflicts of interest. All authors report no conflicts of interest relevant to this article. All authors submitted the ICMJE Form for Disclosure of Potential Conflicts of Interest, and the conflicts that the editors consider relevant to this article are disclosed here.

\section{Marcelo Cordeiro-Santos, MD, $\mathrm{PhD} ;{ }^{1,2}$ Anete Trajman, MD, PhD; $;^{3,4}$ Frank Cobelens, MD PhD; Betina Durovni, MD; ${ }^{3,6}$ Maurício Gonçalves, MSc; ; Samira Bührer-Sékula, PhD; ${ }^{1,7}$ Valeria Saraceni, $M D \mathbf{P h D}^{1,6}$}

Affiliations: 1. Fundação de Medicina Tropical Dr. Heitor Vieira Dourado, Manaus, Amazonas, Brazil; 2. Tropical Medicine Postgraduate Programme, Universidade do Estado do Amazonas, Brazil; 3. Internal Medicine Postgraduate Programme, Universidade Federal do Rio de Janeiro, Rio de Janeiro, Brazil; 4. Montreal Chest Institute, McGill University, Montreal, Canada;
5. Department of Global Health, Academic Medical Center, Amsterdam, The Netherlands; 6. Secretaria Municipal de Saúde, Rio de Janeiro, Brazil; 7. Universidade Federal de Goiás, Instituto de Patologia Tropical e Saúde Pública, Goiânia, Goiás, Brazil.

Address correspondence to Marcelo Cordeiro-Santos, MD, PhD, Tropical Medicine Foundation Dr. Heitor Vieira Dourado, Manaus, Avenida Pedro Teixeira, 25, CEP: 69040-000, Manaus, Amazonas, Brazil (marcelocordeiro.br@gmail.com).

Infect Control Hosp Epidemiol 2014;35(9):1206-1207

(c) 2014 by The Society for Healthcare Epidemiology of America. All rights reserved. 0899-823X/2014/3509-0025\$15.00. DOI: $10.1086 / 677643$

\section{REFERENCES}

1. Sepkowitz KA. Tuberculosis and the health care worker: a historical perspective. Ann Intern Med 1994;120:71-79.

2. Joshi R, Reingold AL, Menzies D, Pai M. Tuberculosis among health-care workers in low- and middle-income countries: a systematic review. PLoS Med 2006;3:e494.

3. Jensen PA, Lambert LA, Iademarco MF, Ridzon R. Guidelines for preventing the transmission of Mycobacterium tuberculosis in health-care settings, 2005. MMWR Recomm Rep 2005;54:1141.

4. World Health Organization (WHO). WHO policy on TB infection control in health-care facilities, congregate settings and households. WHO/HTM/TB/2009.419. Geneva: WHO, 2009.

5. Ministério da Saúde. Secretaria de Vigilância em Saúde. Programa Nacional de Controle da Tuberculose. Manual de recomendações para o controle da tuberculose no Brasil. http://portal.saude.gov.br/portal/arquivos/pdf/manual_de _recomendacoes_controle_tb_novo.pdf. Accessed February 14, 2011.

6. Seidler A, Nienhaus A, Diel R. Review of epidemiological studies on the occupational risk of tuberculosis in low-incidence areas. Respiration 2005;2:431-446.

7. World Health Organization (WHO). WHO endorsements and recommendations. Tuberculosis diagnostics Xpert MTB/RIF test. http://www.who.int/tb/features_archive/factsheet_xpert _may2011update.pdf. Accessed February 14, 2011.

8. Durovni B, Saraceni V, Trajman A, et al. Xpert MTB/RIF pilot roll-out in Brazil: results and lessons learned. In: Abstract Book of the 44th World Conference on Lung Health of the International Union Against Tuberculosis and Lung Disease. Paris: International Union Against Tuberculosis and Lung Disease, 2013:S204. Abstract PC-491-01.

9. Harries AD, Kamenya A, Namarika D, et al. Delays in diagnosis and treatment of smear-positive tuberculosis and the incidence of tuberculosis in hospital nurses in Blantyre, Malawi. Trans $R$ Soc Trop Med Hyg 1997;91:15-17.

10. Tudor C, Van der Walt M, Hill MN, Farley JE. Occupational health policies and practices related to tuberculosis in health care workers in KwaZulu-Natal, South Africa. Public Health Action 2013;3:141-145. 